\title{
Geographical Analysis of Smoking in Leeds: A GIS-Based Location-Allocation Technique for the Optimal Location of Smoking Cessation Services
}

\author{
Mildred Oiza Ajebon, Monday Ohi Asikhia \\ Department of Geography and Regional Planning, University of Benin, Benin City, Nigeria \\ Email: mildoba10@yahoo.com, asikhia@hotmail.com
}

Received April 19, 2013; revised May 20, 2013; accepted June 15, 2013

Copyright (C) 2013 Mildred Oiza Ajebon, Monday Ohi Asikhia. This is an open access article distributed under the Creative Commons Attribution License, which permits unrestricted use, distribution, and reproduction in any medium, provided the original work is properly cited.

\begin{abstract}
Smoking is associated with several illnesses in the UK. Smoking rate in Leeds is higher than the national average. Finding optimal locations for stop-smoking services will be a good place to start in reducing smoking rates. The study utilizes a GIS-Based location-allocation method for the optimal distribution of smoking cessation centres in relation to the spatial distribution of the smoking population in Leeds. The demand for the smoking cessation clinics was estimated based on the 2009 General Life Style (GLS) statistics on age and social class stratification of smoking rates for the UK. Leeds specific rates were then obtained from the 2001 census key statistics data on socioeconomic status and age structure for output areas via Census Area Statistics Website (CASWEB). The research findings show that spatial inequalities in smoking rate exist in output areas of Leeds. Poorer and non-skilled populations are demonstrated to have higher smoking rates compared with wealthier neighbourhoods. The study confirms the capability of GIS-Based location-allocation techniques to be useful modelling tools for determining the best locations for health facilities. The model allocates services in relation to the spatial patterns of demand in a fashion that minimises average travel distance.
\end{abstract}

Keywords: GIS; Location-Allocation; Optimization; Smoking Cessation Services

\section{Introduction}

Smoking is an important driver of spatial variations in mortality in Britain. It is associated with various types of heart diseases and established to be a major risk factor of various types of cancers worldwide ([1] Tomintz et al., 2008). The link between smoking and ill-health has increasingly attracted the attention of health researchers and government alike. Periodic targets are set by the UK government to reduce smoking in the population. One of the major targets of the 2011 Tobacco Control Program for England is to reduce adult smoking to 18.5\% in 2015. This means that stop-smoking services will have to be located in communities where target groups can access them easily ([2] Pearce et al., 2011, [3] Tomintz et al., 2009, [4] Tomintz et al., 2010, [5] Wolfenden et al., 2005). Identifying specific locations that will effectively serve different population groups in different areas presents a typical public-sector planning problem which requires the following fundamental geographical questions to be answered. Where about in Leeds is the smok- ing population located? Are the existing stop-smoking centres optimally distributed in relation to the proportion of the smoking population? If not, what alternative distribution of services will increase accessibility? The study aims to address these questions. The location-allocation methods are used for handling two important issues. Firstly, it attempts to model the geographical locations of the smoking population for the smallest geographical areas possible and second, it attempts to model optimal locations for smoking cessation services in relation to the geographical pattern of demand. The chosen study area is Leeds City with a population estimate of 750,000 . Statistics show that the city has a higher-thannational average smoking rate (26\%) (Healthy Leeds, 2009 to 2012). Smoking has therefore been identified as an important health issue in the area.

\section{Literature Review}

The population of smokers worldwide is estimated to be 1.8 billion accounting for about 5.4 million preventable 
deaths annually ([6] Guindon and Boisclair, 2003). In the UK, smoking rate is higher than the European average contributing to one fifth of all deaths ([7] McEwen et al., 2010, [2] Pearce et al., 2011, [8] Popham, 2011). The World Health Organisation Framework Convention on Tobacco Control suggests the inclusion of smoking cessation support services in national tobacco regulations ([9] Gibson et al., 2010). In the UK, several interventions have been made since 1945 to reduce smoking rates and to prevent people from starting. The government developed a tobacco control policy plan in 1998 to cut overall smoking to $21 \%$ in 2010 . Priority was on targeting vulnerable groups through the provision of smoking cessation services to help smokers quit successfully ([10] Bauld et al., 2007, [9] Gibson et al., 2010, [11] Statistics, 2011, [3] Tomintz et al., 2009). Analysis of the 2009 General Lifestyle Surveys (GLS) reveal that the 1998 target has been met for the general population, little change has however been achieved in the lower socioeconomic groups which have higher estimates of $29 \%$ ([12] ASH Fact Sheet on Smoking Statistics 2011). Though general smoking prevalence in Britain declined steadily between mid-1970s and the 1980s, it now seems to be levelling at 21\% (Table 1). Smoking rate (26\%) in Leeds is higher than the UK average. Finding out where and why smoking rates vary among local populations in Leeds might be a good point to start in reducing smoking rate to the national average.

\subsection{Demographic Character of the Smoking Population in Leeds}

Smoking rate is established in literature to differ among populations. Several demographic variables captured in the general census and other demographic surveys like the GLS are often employed by health researchers in measuring prevalence. These include age structure, socioeconomic classification, education, housing tenure, employment, car ownership, and ethnicity. Heavy smoking is established in literature to vary widely with deprivation ([2] Pearce et al., 2011, [8] Popham, 2011, [13] Richardson, 2001). Highest smoking prevalence is recorded in deprived populations with higher rates in disadvantaged places. Poorer people often use smoking as a temporary relief measure from social distress. Hence poorer smokers are less likely to quit smoking ([8] Popham, 2011, [13] Richardson, 2001). The widening socioeconomic gradient in smoking is attributed to higher rates of smoking cessation among higher social groups and lower rates of successful quit attempts among persons in manual groups ([2] Pearce et al., 2011).

The association between social disadvantage and smoking prevalence is evident across areas in Leeds. Lifestyle surveys suggest even greater inequalities at smaller geographies, ranging from $18 \%$ in sub-urban affluent areas like Wetherby, to a sharp contrast of $46 \%$ in more deprived areas (Seacroft). Targeting smokers in deprived areas is a top priority in health planning because heavy smokers have limited economic resources; spend more money on cigarettes which limits access to healthy foods. For details, see ([14] Healthy Leeds, 2009 to 2012, [1] Tomintz et al., 2008, [4] Tomintz et al., 2010). Spatial pattern in smoking is also strongly defined along age lines. Studies have shown evidence of variations in smoking prevalence by age ([12] ASH Fact Sheet on Smoking [11] Statistics 2011, [15] Foley et al., 2009, [6] Guindon and Boisclair, 2003, [16] Robinson and Harris, 2011, Statistics, 2011). Higher smoking rates have been recorded for persons aged 20-24 since 1998 ([12] ASH Fact Sheet on Smoking Statistics 2011). The oldest groups (60 and above) have the lowest smoking rates.

\subsection{Planning Stop-Smoking Services}

Central to healthcare planning discussions, are the fundamental concepts of service demand and supply. In an ideal scenario, services will be supplied in equal proportions to their demand. In spatial applications, this would mean correctly placing service centres in rural or urban areas to exactly meet the demand for them ([15] Foley et al., 2009). In reality, the existence of mismatches between demand and supply at different spatial levels clearly defines a role for geographers in health facility planning. It has been recommended in literature to locate healthcare centres locally in relation to demand to increase utilization and to minimise distance travelled by poorer people to access available services. The study employs this recommendation by attempting to determine the optimal locations for smoking-cessation clinics using existing statistics on the smoking population in Leeds.

\section{Data and Methods}

2001 census key statistics data on socioeconomic status

Table 1. Smoking rates in England from 1974 to 2009.

\begin{tabular}{|c|ccccccccccc|c|}
\hline \% Smoking Population & $\mathbf{1 9 7 4}$ & $\mathbf{1 9 8 0}$ & $\mathbf{1 9 8 6}$ & $\mathbf{1 9 9 2}$ & $\mathbf{1 9 9 8}$ & $\mathbf{2 0 0 4}$ & $\mathbf{2 0 0 5}$ & $\mathbf{2 0 0 6}$ & $\mathbf{2 0 0 8}$ & $\mathbf{2 0 0 9}$ \\
\hline Men & 51 & 42 & 35 & 29 & 30 & 26 & 25 & 23 & 22 & 22 \\
\hline Women & 41 & 37 & 31 & 28 & 26 & 23 & 23 & 21 & 21 & 20 & 21 \\
\hline All & 45 & 39 & 33 & 28 & 28 & 25 & 24 & 22 & 21 & 21 \\
\hline
\end{tabular}

Source: ([12] ASH Fact Sheet on Smoking Statistics 2011). 
and age structure for output areas was obtained via UK Census Area Statistics Website (CASWEB) to estimate smoking population. The 2009 General Life Style statistics on age and social class stratified smoking rates for UK was used to estimate smoking population of output areas in Leeds. The postcodes of existing thirty-three stop-smoking service centres and forty-four National Health Service (NHS) centres in Leeds were downloaded from NHS database. For mapping purposes, the spatial reference for the centroids of each postcode where clinics and stop-smoking services are located was derived using ordinance survey postcode query facility. Digital boundary data of output areas were obtained via (http://digimap. edina.ac.uk/cdptquery/servlet/Query?useJS=true; accessed $1^{\text {st }}$ March, 2012). Full details on the number of clinics and the locations of existing stop-smoking centres are available at http://www.leedscommunityhealthcare.nhs. uk/what_we_do/specialist_services/stop_smoking_servic e1/smoking_clinics/.

The approach employed in this study is similar to conventional approaches used in health geography. This involves identifying relevant geographic dataset to estimate the smoking-population in Leeds. The smoking population for this study is estimated based on the 2009 General Life Style (GLS) statistics on social class stratification of smoking rates for the UK. Supplementary methods, Gi* statistics and K-Means classification were applied to estimated smoking population data to further explain the spatial variations among population groups. The demand for stop-smoking services by different groups is measured with demographic data. The distribution of stopsmoking facilities forms another layer of information for evaluating stop-smoking service supply in relation to demand. Ultimately, the estimated demand is used as a basis for a more sophisticated location-allocation modelling of different location scenarios. The model was implemented in Arc Workstation 10.0. ArcGIS Desktop10 was used for other GIS analysis and mapping.

\section{Analysis/Results}

\subsection{Estimating Smoking Population of Output-Areas of Leeds}

The analysis began with deriving local estimates of smoking population across Leeds using a variety of national datasets such as household socioeconomic status and age. These are considered critical explanatory indicators of smoking in 2011 NHS tobacco program.

\subsection{Estimating Smoking Population Based on Age}

First, smoking rate is measured using age data from the 2001 census. The GLS smoking rates for age groups is shown in Table 2. Since 1998, persons in age group 20 24 have had the highest smoking rate in England. Groups above 60 years have the lowest rate of 14\%. The 2009 national smoking rate is applied to the population of all 2439 Leeds output areas to measure the number of smokers. The resulting pattern of smoking population distribution across Leeds is shown in Figure 1. The result for Leeds is as expected with highest concentration of smokers around Headingley, an area with high student and young population.

\subsection{Estimating Smoking Population Based on Socioeconomic Class}

The 2001 socioeconomic class data was aggregated into three broad classes namely; managerial and professional; intermediate; routine and manual.

Table 3 shows the 2009 national smoking rate for household heads in three broad socioeconomic classes. It can be seen that routine and manual groups have the highest rates (29\%) for both men and women. Managers and professional have a lower rate of $15 \%$. In all groups, men smoke more than women.

Applying these rates to the local population of Leeds output areas, the distribution of the smoking population by socioeconomic class is shown in Figure 2. Places with high concentration of smokers include Armley, Bramley, Hunslet, Morley North, and Seacroft wards. These areas are associated with socioeconomic deprivation in literature ([1] Tomintz et al., 2008). Comfortable sub-urban areas in the North of Leeds like Wetherby and North wards have relatively lower concentration of smokers. The Headingley area which rated highest in age-estimated smoking population appears to be lower in the social class stratified smoking rate because student

Table 2. Smoking prevalence by age in England, 2009.

\begin{tabular}{|c|c|c|c|c|c|c|}
\hline \multirow{2}{*}{$\begin{array}{c}\text { \% Smoking by age } \\
\text { Age }\end{array}$} & \multicolumn{6}{|c|}{ Age } \\
\hline & 16 - 19 & $20-24$ & $25-34$ & $35-49$ & $50-59$ & $60+$ \\
\hline 1978 & 34 & 44 & 45 & 45 & 45 & 30 \\
\hline 1988 & 26 & 27 & 36 & 36 & 33 & 23 \\
\hline 1998 & 31 & 40 & 35 & 31 & 28 & 16 \\
\hline 2008 & 22 & 30 & 27 & 24 & 22 & 13 \\
\hline 2009 & 24 & 26 & 25 & 25 & 21 & 14 \\
\hline
\end{tabular}

Source: ([12] ASH Fact Sheet on Smoking Statistics 2011). 


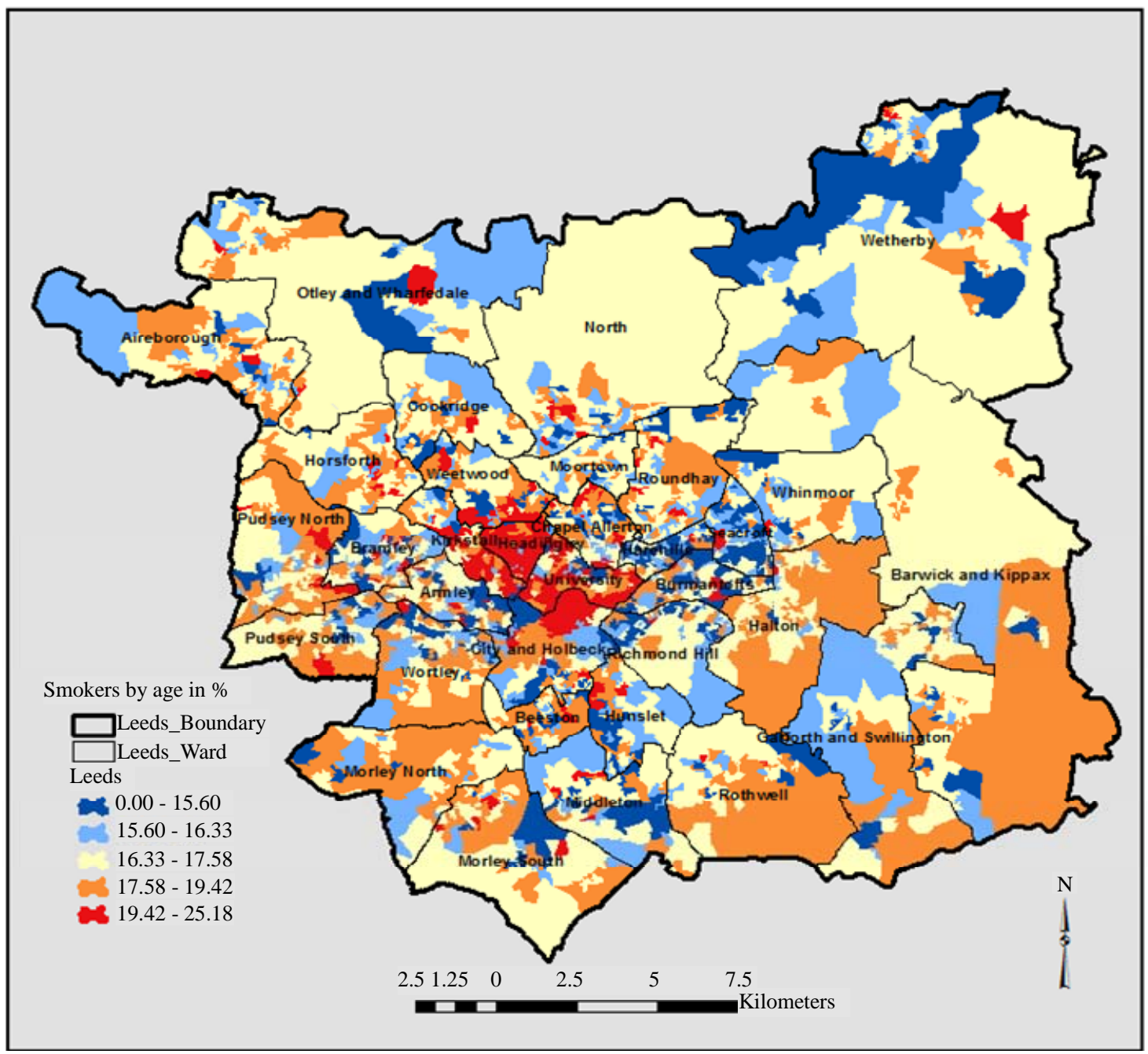

Figure 1. Smoking rate by age groups for Leeds output areas using 2009 estimates.

Table 3. Smoking prevalence by socioeconomic classification in England, 2009.

\begin{tabular}{|c|c|c|c|c|c|c|}
\hline \multirow{2}{*}{ Socioeconomic Classification of Households } & \multicolumn{6}{|c|}{ Percentage smoking cigarettes } \\
\hline & \multicolumn{2}{|c|}{ Men } & \multicolumn{2}{|c|}{ Women } & \multicolumn{2}{|c|}{ Total } \\
\hline Large Employers and Higher Managerial & 12 & & 13 & & 13 & \\
\hline Higher Professional & 11 & 15 & 10 & 14 & 10 & 15 \\
\hline Lower Managerial and Professional & 18 & & 16 & & 17 & \\
\hline \multicolumn{7}{|l|}{ Intermediate } \\
\hline $\begin{array}{l}\text { Intermediate } \\
\text { Small Employers and Own Account }\end{array}$ & $\begin{array}{l}19 \\
23\end{array}$ & 21 & $\begin{array}{l}16 \\
21\end{array}$ & 19 & $\begin{array}{l}17 \\
22\end{array}$ & 20 \\
\hline \multicolumn{7}{|l|}{ Routine and manual } \\
\hline Lower Supervisory and Technical & 25 & & 27 & & 26 & \\
\hline Semi-Routine & 31 & 30 & 26 & 27 & 28 & 29 \\
\hline Routine & 34 & & 30 & & 32 & \\
\hline Total & 22 & & 20 & & \multicolumn{2}{|c|}{21} \\
\hline
\end{tabular}

Source: ([12] ASH Fact Sheet on Smoking Statistics 2011). 




Figure 2. Smoking rate by socioeconomic class in Leeds output areas using 2009 GLS estimates.

households are not included in the socioeconomic groups used. The inequality in smoking observed in populations and across areas in Leeds supports previous findings on the subject. [2] Pearce et al. (2011), [8] Popham (2011), [13] Richardson (2001), [16] Robinson and Harris (2011) and others found a strong relationship between heavy smoking and deprivation.

\subsection{Smoking Hotspots and Area Profiling of Leeds}

Using the 2009 socioeconomic-class-aggregated smoking population data, the $\mathrm{Gi}^{*}$ statistics hotspot method was applied to identify areas with lower or higher smoking rates than the Leeds average. This is helpful for prioritising and targeting smoking intervention strategies. The red areas in Figure 3 are identified as areas with higher than average rates of smoking in Leeds. These represent health action zones (Health Pudsey, Beeston, Morley South, Middleton, Hunslet, Bramley, Seacroft) where healthcare planners might wish to channel more inter- vention resources. The white areas have average smoking rates and the blue areas have relatively lower rates. Notice that the University and Headingley areas are again classified as having lower rates of smoking because of the omission of student households.

Given the slight variation in the distribution of smoking population observed using the age and social class national rates, a general area profile of Leeds output areas was developed using K-Means cluster statistics. 25 of the key variables identified used by [17] Vickers and Rees (2007) for creating output area classification for the UK were analysed. They include age, marital status, health, economic activity; social class, ethnicity, housing tenure, car ownership etc. The area classification map in Figure 4 provides good description of what areas are like in Leeds. The area profile shows that Headingley and University wards are student areas, Seacroft and most output areas with heavy smoking are hard pressed, Harehills is an ethnic minority zone, Wetherby and North wards are more comfortable sub-urban areas. In line with 


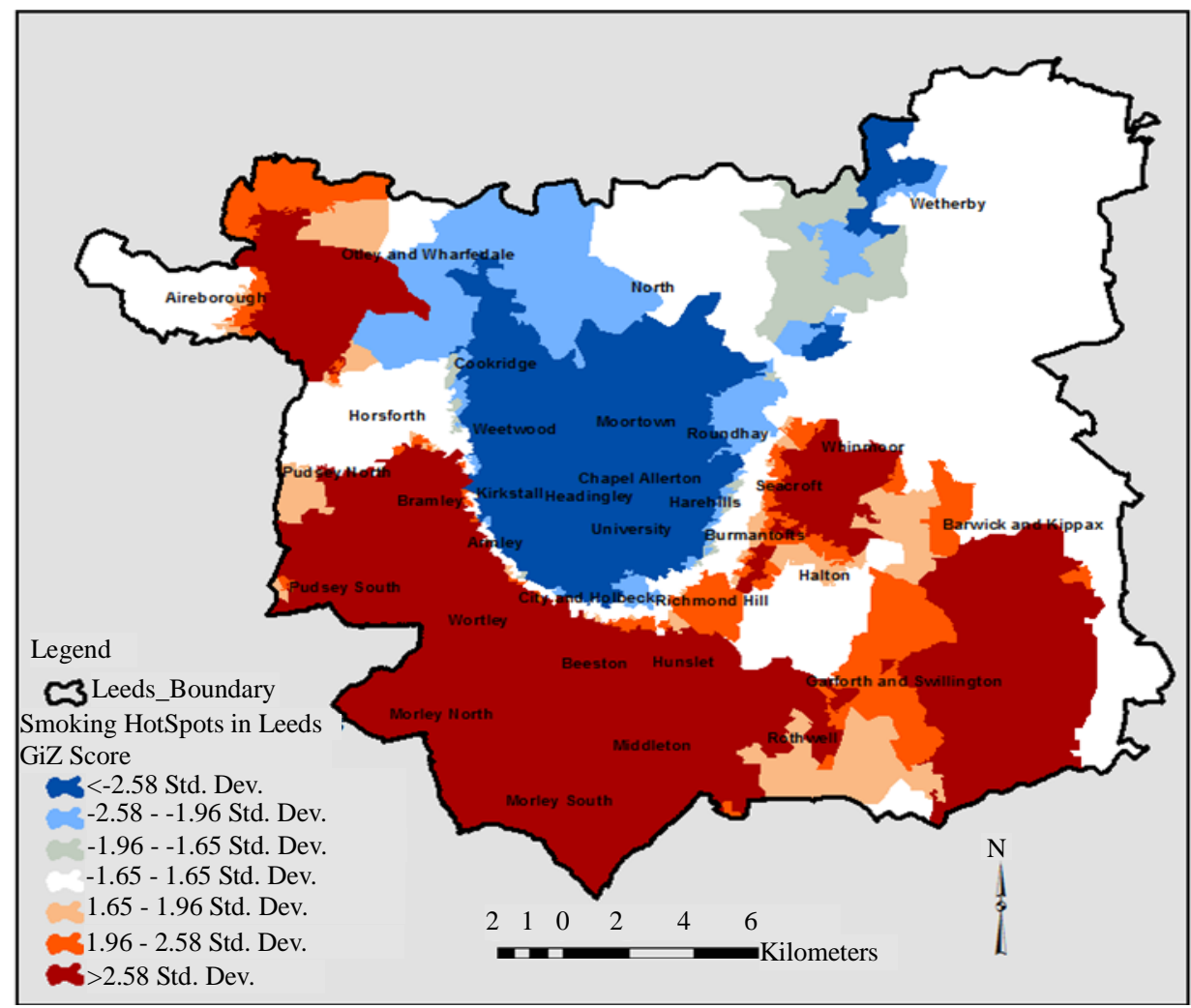

Figure 3. Smoking hotspots in Leeds.



Figure 4. Geodemographic classification of Leeds. 
previous findings, heavy smoking can thus be clearly seen to be associated with deprivation in Leeds. ([2] Pearce et al., 2011, [8] Popham, 2011, [13] Richardson, 2001, [18] Shankar et al., 2010).

\subsection{Spatial Distribution of Existing Health Centres in Relation to Demand}

The distribution of existing stop-smoking services was examined in relation to estimated spatial pattern of smoking in Leeds. Figure 5 shows a mismatch between demand and supply of health services. Like most urban centres, services are concentrated in central Leeds ([15] Foley et al., 2009). While the north-end and outlying risk areas do not have local access to services, the university areas have more services than they might need. This is further complicated by the fact that not all centres are opened every day of the week. Services are only available at certain times of the day when clinics are opened. This further reduces accessibility of smokers to existing services and market penetration.

\subsection{Optimal Location of Stop-Smoking Services in Leeds}

In order to provide a blue print for future development of smoking cessation centres, a GIS-Based location-allocation method is employed to find efficient distribution of stop-smoking centres Several research findings have proven location-allocation methods to be a useful modelling technique for determining best locations for facilities in relation to spatial patterns of demand ([15] Foley et al., 2009, [19] Rahman and Smith, 2000, [20] Smith et al., 2011, [1] Tomintz et al., 2008, [3] Tomintz et al., 2009, [4] Tomintz et al., 2010). The model allocates services in relation to the distribution of demand in a fashion that minimises average travel distance. Figure 6 shows the optimal locations for stop-smoking services.

In the UK, free smoking-cessation services are traditionally located in existing NHS centres. Experts have suggested that stop-smoking services should be located away from NHS centres to very local community levels to encourage the utilization by smokers (Wolfenden et al., 2005). In this study, the optimal location models are used to evaluate the distribution of the existing centres in Leeds. Only 15 (examples of Horsforth, Morley Centre, Rothwell, Ortley, Purdsey) stop-smoking centres are in near-optimal locations.

The NHS policy is designed to vary the locations of centres quarterly. Different numbers of clinics are operational on different days and times of the week. Available



Figure 5. Comparing the distribution of existing stop-smoking service in relation to the population of smokers. 




Figure 6. Optimal location for 33 existing stop-smoking service centres.

data for this study shows that highest numbers of clinics (9) are operational on Mondays and lowest numbers of clinics (4) on Fridays (see Appendix 1 for details). Though this policy has the merit of ensuring that services are spatially mobile, it however has a negative implication for accessibility to services by most smokers. If locations must be varied quarterly due to certain circumstances, then optimal locations for specific numbers of clinics operational on different days must be determined. Figures $\mathbf{7}$ and $\mathbf{8}$ show two different scenarios for nine and four optimal stop-smoking centres respectively. Three of the nine clinics (Morley, Scothall and Newcroft) operational on Mondays are located near-optimal locations. Seacroft centre is the only one of the operational Friday clinics in optimal location. This means that users will have to travel a longer distances on those days to utilize services. Similar relationships are expected on Tuesdays Wednesdays and Thursdays. Overall, fixed optimal locations for all clinics is the best scenario for maximum accessibility and greater utilization of services. This will provide more effective and permanent smoking cessation support to target groups.

A forth scenario of what locations will be optimal if all NHS clinics listed in Appendix 1 were to be fixed loca- tions for smoking cessation services is examined. The analysis (Figure 9) show some existing NHS centres to be in near-optimal locations. These include Hortsforth clinic, Seacroft, Morley South, Pudsey South, Otley and Rothwell clinics. Future provision of additional stopsmoking centres might consider locating in areas with optimally located NHS centre without current access to services. These include Wetherby Health Centre, Garforth Clinic, and Yeadon Community Healthcare.

\section{Conclusions}

This study demonstrates the benefit of integrating the analytical power of geographic information tools and demographic information in public sector planning. It has the merit of estimating smoking population at an output area level. It is recognised that census data at fine geographical scales are blurred to increase confidentiality.

The research findings show that spatial inequalities in smoking rate exist in output areas of Leeds. Most wards in the southern ends of Leeds are identified as smoking hotspots. Evaluating the Location of existing stopsmoking clinics shows that most centres are sub-optimally located and concentrated in the Leeds City centre. 


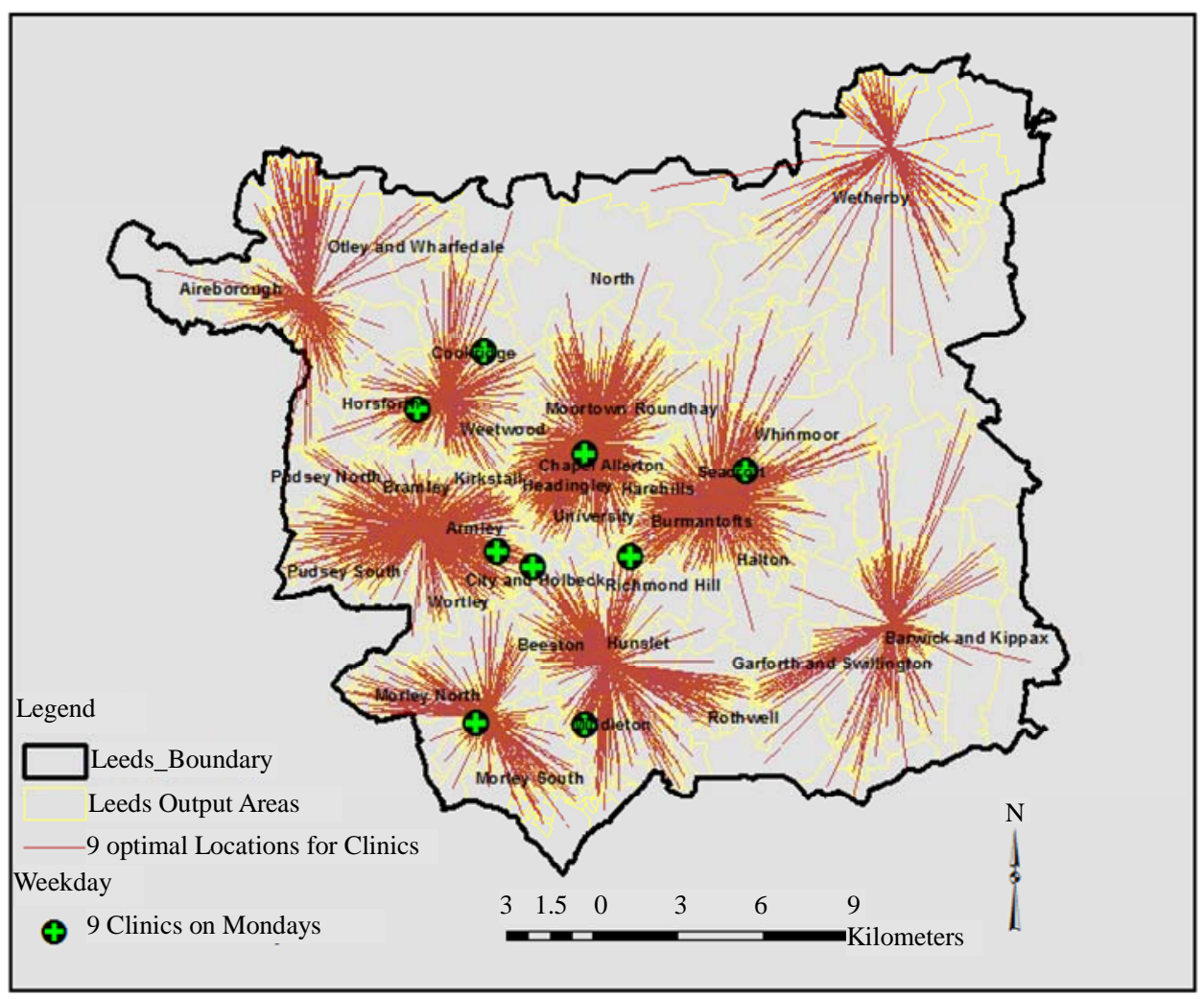

Figure 7. Optimal location for 9 operational stop-smoking service centres.

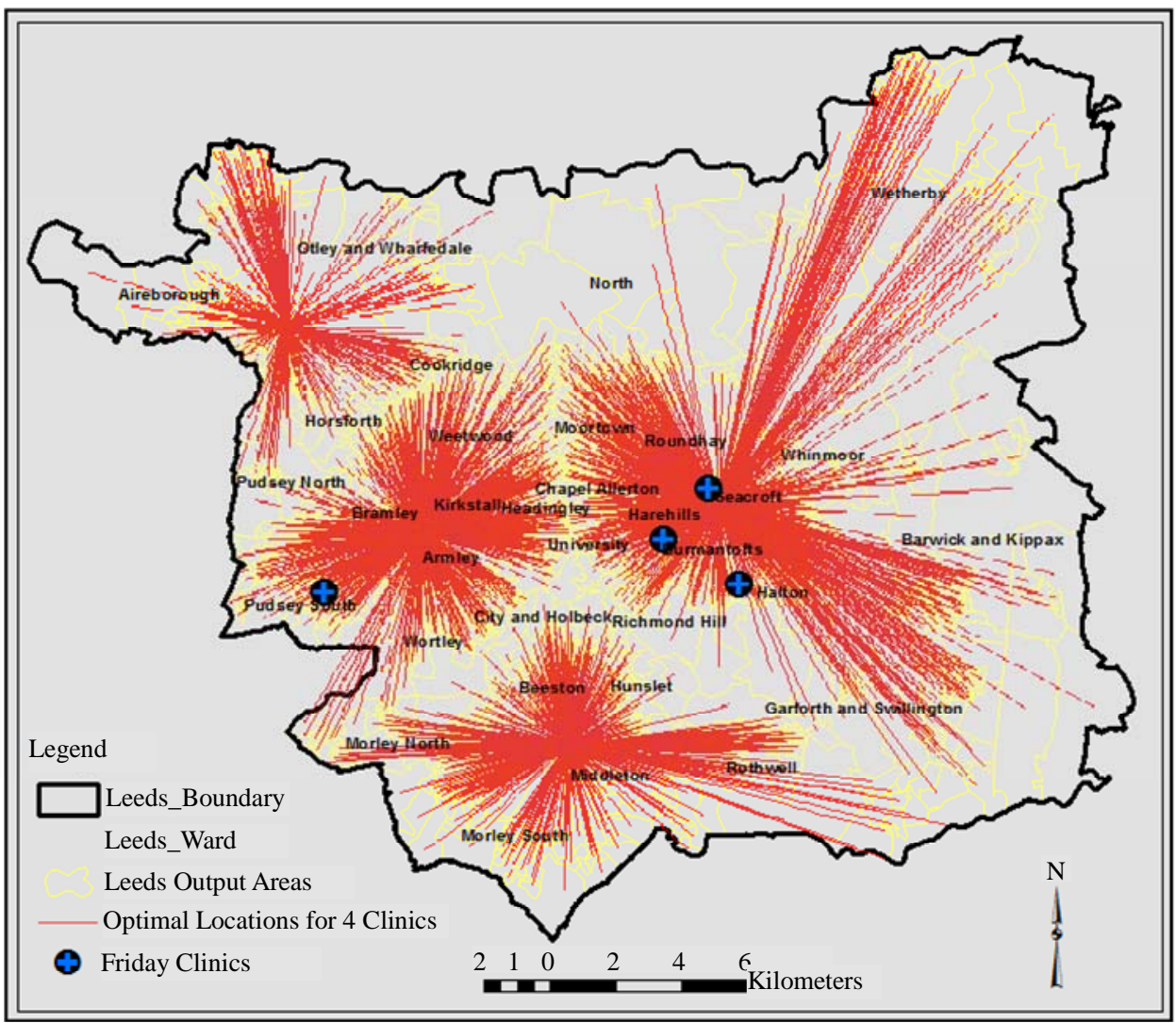

Figure 8. Optimal location for 4 operational stop-smoking service centres. 


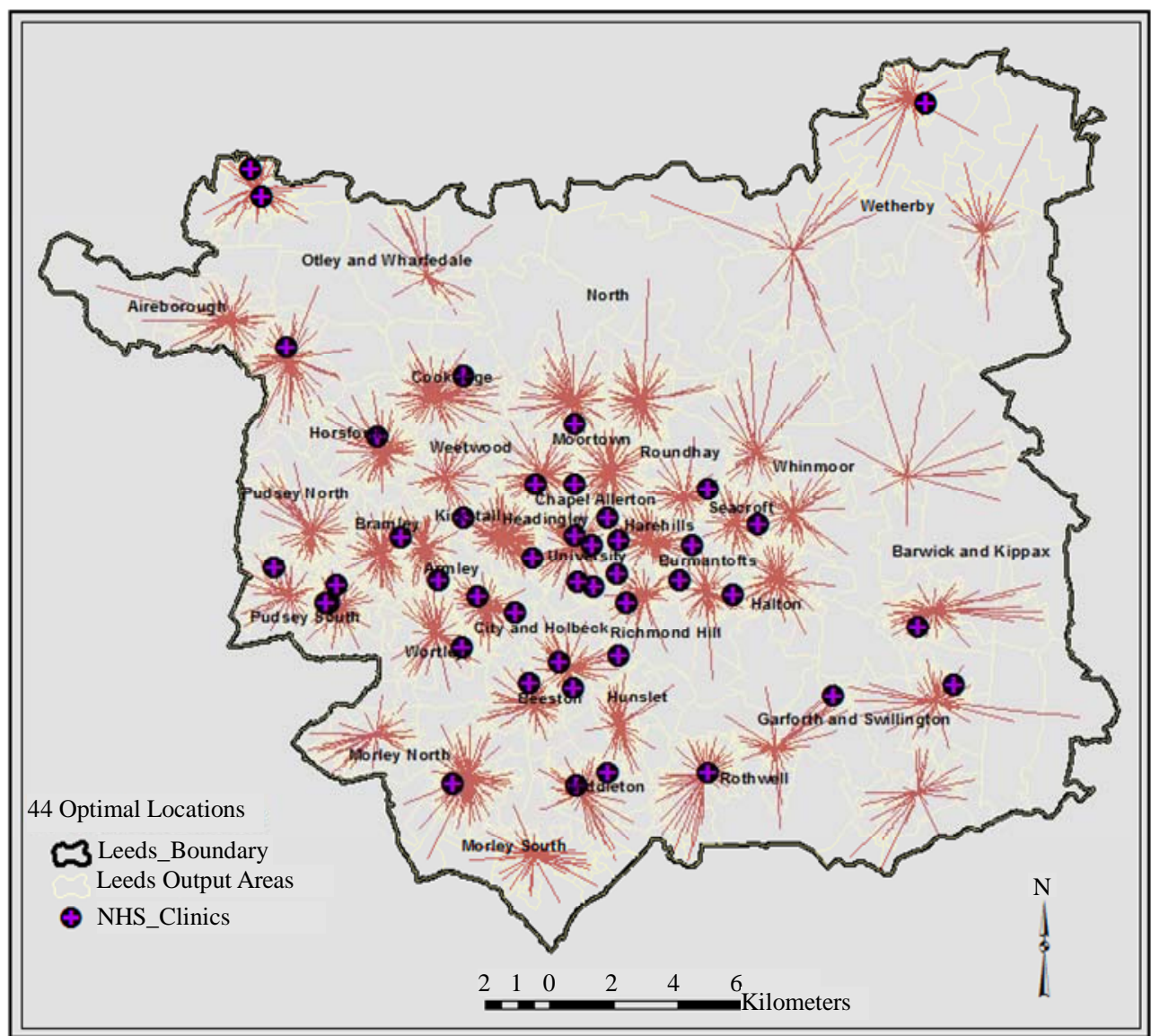

Figure 9. Optimal location if all NHS centres were fixed locations for stop-smoking services.

Thirty-three alternative locations developed using Location-allocation Methods promises to be an effective and preferred way of distributing fixed stop-smoking services across Leeds. Derived information products are easy to visualise and understand by policy makers ([21] Vonk et al., 2007). The results of the analyses will facilitate planning and policy making processes for effective targeting of risk population in Leeds.

However, reliance on the 2001 census data in the study is considered a major limitation. Though, the 2001 census is a rich source of demographic and socioeconomic data, it is fairly outdated. Information on smoking and related lifestyle information are not collected. Using the 2009 GLS statistics for deriving estimates of the smoking population from census data has serious implications for accuracy and reliability of results. It is argued that using one variable at a time to estimate smoking population might not be a reliable method because classification of areas into smoking groups might vary slightly with the demographic indicators used. [4] Tomintz et al. (2010) argue that micro-simulation techniques based on deterministic reweighting and integration of census and GLS data might be more reliable ways of combining key indicators of smoking risks to produce better estimates upon which further analysis and policy decisions can be made.

The conventional method used for resolving location-allocation problems modelled alternate locations of services and demand as discrete points represented by centroids of output areas under consideration. This might be insufficient for handling dense demand data especially where a number of complex factors shaping location decisions (such as cost, time and uncertainties of potential sites) are not considered ([22] Murat et al., 2010). Distance estimation in the location-allocation algorithm used is based on Euclidean principles. Spatial linkages and modes of transportation are not considered in estimating distance in the model. Some studies have moved beyond Euclidean distance by using GIS to produce robust models which consider actual travel time along networks. Future studies and modifications of the model should consolidate on incorporating a wider range of demographic and local environmental conditions which might modify what is considered optimal for locating stopsmoking services in realistic terms.

Despite inherent conceptual flaws and perceived mathematical sophistication of location-allocation methods, the study in line with several studies, demonstrates the effectiveness of the method in providing a useful 
guide in location decision problem solving ([15] Foley et al., 2009, [7] McEwen et al., 2010, [19] Rahman and Smith, 2000, [1] Tomintz et al., 2008, [3] Tomintz et al., 2009, [4] Tomintz et al., 2010).

\section{REFERENCES}

[1] M. N. Tomintz, G. P. Clarke and J. E. Rigby, "The Geography of Smoking in Leeds: Estimating Individual Smoking Rates and the Implications for the Location of Stop Smoking Services,” Area, Vol. 40, No. 3, 2008, pp. 341-353. doi:10.1111/j.1475-4762.2008.00837.x

[2] J. Pearce, R. Barnett and G. Moon, "Sociospatial Inequalities in Health-Related Behaviours: Pathways Linking Place and Smoking," Progress in Human Geography, Vol. 36, No. 1, 2011, pp. 3-24.

[3] M. N. Tomintz, G. P. Clarke and J. E. Rigby, "Planning the Location of Stop Smoking Services at the Local Level: A Geographic Analysis,” The Journal of Smoking Cessation, Vol. 4, No. 2, 2009, pp. 61-73. doi:10.1375/jsc.4.2.61

[4] M. N. Tomintz, G. P. Clarke and J. E. Rigby, “A Microsimulation Model to Find Optimal Locations for Smoking Cessation Services,” Royal Geographical Society, Vol. 40, 2010, p. 21.

[5] L. Wolfenden, J. Wiggers, J. Knight, E. Campbell, A. Spigelman, R. Kerridge and K. Moore, "Increasing Smoking Cessation Care in a Preoperative Clinic: A Randomized Controlled Trial," Preventive Medicine, Vol. 41, No. 1, 2005, pp. 284-290. doi:10.1016/j.ypmed.2004.11.011

[6] G. E. Guindon and D. Boisclair, "Past, Current and Future Trends in Tobacco Use," WHO Tobacco Control Papers, Vol. 63, 2003.

[7] A. McEwen, L. Condliffe and A. Gilbert, "Promoting Engagement with a Stop Smoking Service via Pro-Active Telephone Calls,” Patient Education and Counseling, Vol. 80, No. 2, 2010, pp. 277-279. doi:10.1016/j.pec.2009.11.009

[8] F. Popham, "To What Extent Can Deprivation Inequalities in Mortality and Heart Disease Incidence amongst the Working Aged in Scotland Be Explained by Smoking? Relative and Absolute Approaches,” Health \& Place, Vol. 17, No. 5, 2011, pp. 1132-1136. doi:10.1016/j.healthplace.2011.05.008

[9] J. E. Gibson, R. L. Murray, R. Borland, K. M. Cummings, G. T. Fong, D. Hammond and A. Mcneill, "The Impact of the United Kingdom's National Smoking Cessation Strategy on Quit Attempts and Use of Cessation Services: Findings from the International Tobacco Control Four Country Survey," Nicotine \& Tobacco Research, Vol. 12, Supplement 1, 2010, pp. S64-S71. doi:10.1093/ntr/ntq119

[10] L. Bauld, K. Judge and S. Platt, “Assessing the Impact of Smoking Cessation Services on Reducing Health Inequalities in England: Observational Study,” Tobacco Control,
Vol. 16, No. 6, 2007, pp. 400-404. doi:10.1136/tc.2007.021626

[11] T. N. I. C. L. Statistics, "Statistics on Smoking: England 2011," The Health and Social Care Information Centre, 2011.

[12] ASH Fact Sheet on Smoking Statistics, "Smoking Statistics: Who Smokes and How Much," Fact Sheets on Smoking Statistics, Action on Smoking and Health, 2011.

[13] K. Richardson, "Smoking, Low Income and Health Inequalities: Thematic Discussion Document," Report for Action on Smoking and Health and the Health Development Agency, 2001.

[14] Healthy Leeds, "Health and Wellbeing Partnership Plan: Improving Health and Reducing Health Inequalities in Leeds," Healthy Leeds Partnership Initiative, 2009 to 2012.

[15] R. Foley, M. C. Charlton and A. S. Fotheringham, "GIS in Health and Social Care Planning," National Centre for Geocomputation, 2009. http://eprints.nuim.ie/2990/1/FoleyCharltonFotheringham _Final.pdf.

[16] S. Robinson and H. Harris, "Smoking and Drinking among Adults, 2009,” General Lifestyle Survey, Office for National Statistics, 2011, 84 pp.

[17] D. Vickers and P. Rees, "Creating the UK National Statistics 2001 Output Area Classification,” Journal of the Royal Statistical Society: Series A (Statistics in Society), Vol. 170, No. 2, 2007, pp. 379-403. doi:10.1111/j.1467-985X.2007.00466.X

[18] A. Shankar, A. Mcmunn and A. Steptoe, "Health-Related Behaviors in Older Adults: Relationships with Socioeconomic Status,” American Journal of Preventive Medicine, Vol. 38, No. 1, 2010, pp. 39-46. doi:10.1016/j.amepre.2009.08.026

[19] S. Rahma and D. K. Smith, "Use of Location-Allocation Models in Health Service Development Planning in Developing Nations," European Journal of Operational Research, Vol. 123, No. 3, 2000, pp. 437-452. doi:10.1016/S0377-2217(99)00289-1

[20] D. M. Smith, J. R. Pearce and K. Harland, "Can a Deterministic Spatial Microsimulation Model Provide Reliable Small-Area Estimates of Health Behaviours? An Example of Smoking Prevalence in New Zealand," Health \& Place, Vol. 17, No. 2, 2011, pp. 618-624. doi:10.1016/j.healthplace.2011.01.001

[21] G. Vonk, S. Geertman and P. Schot, "A SWOT Analysis of Planning Support Systems," Environment and Planning A, Vol. 39, No. 7, 2007, pp. 1699-1714. doi:10.1068/a38262

[22] A. Murat, V. Verter and G. Laporte, "A Continuous Analysis Framework for the Solution of Location-Allocation Problems with Dense Demand," Computers \& Operations Research, Vol. 37, No. 1, 2010, pp. 123-136. doi:10.1016/j.cor.2009.04.001 


\section{Appendix}

Appendix 1. Locations of existing stop-smoking service centres in Leeds.

\begin{tabular}{|c|c|c|c|c|c|c|}
\hline Postcode & $\mathbf{X}$ & $\mathbf{Y}$ & Clinic & Period of Day & Weekday & Clinic Name \\
\hline LS10 2PT & 431293 & 431614 & 1 & Mornings & Wednesday & Hunslet Health Centre \\
\hline LS10 3JA & 431441 & 429591 & 2 & Afternoons & Tuesday & South Leeds Youth Hub \\
\hline LS10 4HT & 429946 & 427619 & 3 & Tuesdays & Monday & Middleton Community Health Centre \\
\hline LS11 5LQ & 429840 & 430645 & 4 & Evenings & Thursday & Parkside Community Health Centre \\
\hline LS11 8BS & 429403 & 431389 & 5 & Mornings & Tuesday & Beeston Hill Community Health Centre \\
\hline LS12 1HU & 428105 & 432905 & 6 & Afternoons & Monday & Priory View Medical Centre \\
\hline LS12 1JE & 428025 & 432919 & 7 & Mornings & Wednesday & Thornton Medical Centre \\
\hline LS12 3HD & 426894 & 433419 & 8 & Tuesdays & Mondays & Armley Moor Health Centre \\
\hline LS12 5SG & 426375 & 431867 & 9 & Afternoons & Wednesday & Wortley Beck Health Centre \\
\hline LS13 3EJ & 424464 & 435218 & 10 & Afternoons & Thursday & Bramley Clinic \\
\hline LS14 6PF & 435613 & 436186 & 11 & Afternoons & Monday & Seacroft Clinic \\
\hline LS14 6UH & 434941 & 434607 & 12 & Mornings & Tuesdays & Seacroft Hospital \\
\hline LS15 7HR & 434863 & 433469 & 13 & Afternoons & Friday & Halton Clinic \\
\hline LS15 7JY & 436132 & 434509 & 14 & Afternoons & Thursday & Newman Centre (St. Theresa's Church Hall) \\
\hline LS16 5BE & 426296 & 437537 & 15 & Mornings & Tuesday & West Park Centre \\
\hline LS16 7QD & 426419 & 440164 & 16 & Afternoons & Monday & Holt Park Health Centre \\
\hline LS17 5JD & 429182 & 439111 & 17 & Afternoons & Wednesday & Northcall Community Centre, Cramner Bank \\
\hline LS18 4SE & 424086 & 438226 & 18 & Evenings & Monday & New Croft Surgery \\
\hline LS2 9NS & 429442 & 434115 & 19 & Afternoons & Wednesday & Leeds General Infirmary \\
\hline LS21 2LY & 419767 & 446481 & 20 & Mornings & Thursday & Wharfedale General Hospital \\
\hline LS26 0UE & 434068 & 428034 & 21 & Evenings & Wednesday & Rothwell Health Centre \\
\hline LS27 9NB & 426109 & 427683 & 22 & Evenings & Monday & Morley Health Centre \\
\hline LS28 7BE & 422315 & 433342 & 23 & Evenings & Tuesday & Pudsey Leisure Centre \\
\hline LS28 7XP & 422241 & 433227 & 24 & Mornings & Friday & Pudsey Health Centr \\
\hline LS5 3DB & 426409 & 435836 & 25 & Afternoons & Thursday & Kirkstall Health Centre \\
\hline LS7 3DT & 429974 & 436727 & 26 & Evenings & Monday & Scott Hall Sports Centre \\
\hline LS7 4SA & 431050 & 436365 & 27 & Mornings & Thursday & Chapel Allerton Hospital \\
\hline LS8 3BA & 433945 & 436424 & 28 & Mornings & Friday & The Lodge Medical Centre \\
\hline LS9 6AU & 432595 & 434850 & 29 & Mornings & Friday & Bellbrooke Surgery \\
\hline LS9 7ST & 431242 & 434100 & 30 & Afternoons & Wednesday & Lincoln Green Medical Centre \\
\hline LS9 7TF & 431768 & 434663 & 31 & Afternoons & Thursday & St James’s University Hospital Gledhow Wing \\
\hline LS9 8NG & 431523 & 433230 & 32 & Afternoons & Monday & Richmond Hill Children's Centre \\
\hline LS9 9EF & 433169 & 433885 & 33 & Afternoons & Tuesday & East Leeds Health Centre \\
\hline
\end{tabular}

